\title{
Retrospective Analysis of Mortality Cases in Advanced and Metastatic Solid Tumors With Concurrent Prerenal Azotemia
}

\author{
TZU-YAO LIAO and CHUANG-CHI LIAW \\ Division of Hemato-Oncology, Department of Internal Medicine, \\ Chang-Gung Memorial Hospital and Chang-Gung University College of Medicine, Taoyuan, Taiwan, R.O.C.
}

\begin{abstract}
Background/Aim: A retrospective study of cases with metastatic or advanced solid tumors complicated with AKI (acute kidney injury) with prerenal azotemia. Patients and Methods: Criteria included: (1) advanced or metastatic solid tumors that led to mortality; (2) prerenal azotemia identified upon renal function evaluation and (3) $\mathrm{BUN}$ to $\mathrm{Cr}$ ratio $(B C R) \geq 15$. We also compared the outcomes of patients with $B C R>20$ with those of patients with $B C R=15-20$. Results: A total of 218 patients with solid tumors were enrolled. One hundred and forty (64\%) and 78 (36\%) patients had BCR>20 and 15-20, respectively. Before AKI occurrence, 136 (62\%) had thromboembolic complications and 96 (44\%) paraneoplastic syndromes. Median survival time was 1 week in all patients. Median survival time was statistically different between the groups with BCR15-20 and $B C R>20$ ( $p<0.005$, log-rank test). Conclusion: Cancer patients with concurrent AKI and prerenal azotemia carry a very poor prognosis.
\end{abstract}

Acute kidney injury (AKI) is defined as abrupt kidney damage resulting in the impairment of renal function within a few hours or days $(1,2)$. Understanding the pathogenesis of AKI during critical illness and developing therapeutic strategies for AKI based on the different possible etiologies are necessary (3). During AKI, cytokines are released from leukocytes and renal tubular cells in the injured kidney (4), and an inflammatory response occurs within the kidney after an episode of AKI (5). Prerenal azotemia, one of the causes

This article is freely accessible online.

Correspondence to: Chuang-Chi Liaw, MD, Division of HematoOncology, Department of Internal Medicine, Chang-Gung Memorial Hospital, 5, Fusing St., Gueishan Township, Taoyuan City, 333, Taiwan, R.O.C. Tel: +88633281200 , ext 8825, Fax: +8863278211 , e-mail: e102309@adm.cgmh.org.tw

Key Words: Malignancy, acute kidney injury, prerenal azotemia, BUN to Cr ratio. of AKI, is defined as an increase in the blood concentration of nitrogen metabolism products, such as urea and creatinine (Cr) (6).

A blood urea nitrogen (BUN) to $\mathrm{Cr}$ ratio $(\mathrm{BCR})>20$ is used to distinguish prerenal azotemia and acute tubular necrosis, and high BCR patients have a higher hospital mortality (7). However, BCR is reported to have poor discriminatory ability in distinguishing prerenal AKI from intrinsic AKI (8). AKI is an important cause of morbidity and mortality in cancer patients, resulting in further complications $(9,10)$. Hence, AKI should be rapidly diagnosed and managed.

We designed a retrospective study including patients with metastatic or advanced solid tumors and with concurrent AKI with prerenal azotemia. We studied the clinical outcomes between two groups: one with a BCR 15-20 and the other with a $\mathrm{BCR}>20$.

\section{Patients and Methods}

Patients. This retrospective case series was conducted between June 2008 and December 2019. Data were collected from 947 patients hospitalized in the oncology Department of the Chang-Gung Memorial Hospital. Because the data was mainly sourced from a single physician with expertise in urological cancers, most of these patients had urothelial carcinomas. Of these patients, $218(23 \%)$ were documented to have prerenal azotemia.

The selection criteria included the following: 1) advanced or metastatic solid tumors resulting in mortality; 2) prerenal azotemia, as identified by renal function examination with the elevation of serum BUN and Cr levels; and 3) a BCR $>15$.

Ethics approval and consent to participate. The institutional review board/ethics committee determined that informed consent was not required. This study was approved by the Institutional Review Board (the "IRB") of Chang Gung Medical Foundation on 2020/02/09. IRB No.: 202000126B0.

Clinical and laboratory investigations. The patients often had thromboembolic complications and paraneoplastic syndromes. Common thromboembolism-associated complications included loss of consciousness and mental change, pulmonary venous obstructive syndrome, and iliofemoral venous obstruction or thrombosis. Due 
Table I. Clinical characteristics of the 218 cancer patients with prerenal azotemia.

\begin{tabular}{lc}
\hline Characteristics & No. of patients (\%) \\
\hline Age (years) & $68(32-93)$ \\
$\quad$ Median (range) & \\
Gender & $137 / 81$ \\
$\quad$ Male/Female & \\
Primary tumor sites $(\mathrm{N}=218)$ & $123(56)$ \\
Urothelial cancer & $95(44)$ \\
Non-urothelial cancer & $218(100)$ \\
BUN to Cr ratio (BCR) & $140(64)$ \\
$>20$ & $78(36)$ \\
15-20 & $136(62)$ \\
Associated with thromboembolic complications & $96(44)$ \\
Associated with paraneoplastic syndrome & \\
\hline
\end{tabular}

to the difficulty in obtaining a definite diagnosis, cerebral thromboembolic complications could only be clinically suspected (11-13). Paraneoplastic syndromes included cachexia syndrome (a weight loss of $>5 \%$ within six months, with reduced food intake and muscle wasting), neoplastic fever (tumor-related fever that responds well to the naproxen test) and hypercalcemia (11-13).

Laboratory examinations included complete blood counts (CBC), renal function test, D-dimer and C-reactive protein (CRP). D-dimer conducted using enzyme-linked immunosorbent assay. Severe anemia was defined as hemoglobin $(\mathrm{Hb})$ levels less than $8 \mathrm{~g} / \mathrm{dl}$. Leukocytosis was defined as leukocyte counts greater than $15,000 / \mu \mathrm{l}$ and/or neutrophil counts greater than $12,000 / \mu$ l. Leukopenia was defined as leucocyte counts less than $2,000 / \mu \mathrm{l}$ and/or neutrophil counts less than $1,000 / \mu 1$. Thrombocytosis was defined as platelet counts greater than $400,000 / \mu 1$. Thrombocytopenia was defined as platelet counts less than $100,000 / \mu 1$. Presence of blast or immature myeloid cells was obtained from the differential counts of WBC. The elevation of BUN, Cr levels and BCR were greater than $21 \mathrm{mg} / \mathrm{dl}, 1.3 \mathrm{mg} / \mathrm{dl}$ and 15 , respectively. For the purpose of the study of prerenal azotemia, we divided patients into two groups, those with BCR $>20$ and those with BCR 15-20. The cut off D-dimer and CRP values were $500 \mathrm{ng} / \mathrm{ml}$ and $5 \mathrm{mg} / \mathrm{l}$, respectively. High D-dimer and CRP levels were defined as values greater than $5,000 \mathrm{ng} / \mathrm{ml}$ and greater than $50 \mathrm{mg} / \mathrm{l}$, respectively.

Statistical methods. Continuous data (presented as mean \pm standard deviation) were used to determine the BUN, Cr, BCR, D-dimer, and CRP. The survival time was calculated from the occurrence of prerenal azotemia to death, and survival curves were determined using the Kaplan-Meier method. Significant differences between survival curves were measured using the log-rank test. The Chisquared test was used to detect differences between subgroups, and a $p$-value $<0.05$ was considered statistically significant.

\section{Results}

The patients' clinical characteristics are shown in Table I. There were 218 patients with solid tumors enrolled. The population consisted of 137 men and 81 women, with an age range of 32 to 93 years.
There were 123 patients $(56 \%)$ who had primary malignancies of the urothelium, including that of the bladder $(n=77)$, renal pelvis $(n=33)$, and ureters $(n=13)$. The remaining 95 patients $(44 \%)$ had the following cancer sites: lung $(n=16)$, breast $(n=9)$, renal $(n=13)$, prostate $(n=5)$, colorectum $(n=9)$, pancreas $(n=6)$, stomach $(n=7)$, hepatobiliary tract $(n=3)$, esophagus $(n=7)$, head and neck $(n=5)$, and others $(n=10)$. There were $140(64 \%)$ and 78 (36\%) patients, respectively, who had $\mathrm{BCR}>20$ and $\mathrm{BCR}=15-20$, respectively. The mean values of $\mathrm{BUN}$, creatinine, and BCR in the group that had BCR values greater than 20 were $64 \pm 36 \mathrm{mg} / \mathrm{dl}(30 \mathrm{mg} / \mathrm{dl}$ to $266 \mathrm{mg} / \mathrm{dl})$, $2.2 \pm 1.2 \mathrm{mg} / \mathrm{dl}(1.3 \mathrm{mg} / \mathrm{dl}$ to $84 \mathrm{mg} / \mathrm{dl})$, and $29.2 \pm 9.1(20.1$ to 52.9), respectively. The mean values of BUN, creatinine, and $\mathrm{BCR}$ in the other group $(\mathrm{BCR}=15-20)$ were $49 \pm 24 \mathrm{mg} / \mathrm{dl}$ $(27 \mathrm{mg} / \mathrm{dl}$ to $128 \mathrm{mg} / \mathrm{dl}), 2.9 \pm 1.4(1.4 \mathrm{mg} / \mathrm{dl}$ to $8.1 \mathrm{mg} / \mathrm{dl})$ $\mathrm{mg} / \mathrm{dl}$, and $17.3 \pm 1.5$ (15.1 to 19.8 ), respectively.

All patients had metastatic or advanced disease. There were 136 patients (62\%) who had thromboembolic complications and 96 patients $(44 \%)$ who had paraneoplastic syndromes. Common thromboembolic complications included cerebral thrombosis $(n=79)$, pulmonary venous obstructive syndrome $(n=57)$, iliofemoral vein obstruction/thrombosis $(n=18)$, inferior venous cava thrombosis $(n=6)$, sub-clavicular and jugular obstruction/thrombosis $(n=2)$, and paraneoplastic pain $(n=23)$. The common paraneoplastic syndromes were cachexia syndrome $(n=94)$, hypercalcemia $(n=6)$, and neoplastic fever $(n=4)$.

The laboratory findings of the whole cohort and the $\mathrm{BCR}>20$ and $\mathrm{BCR}=15-20$ groups are shown in Table II. Ddimer was tested for 188 patients. The mean values were $6630 \pm 4128 \mathrm{ng} / \mathrm{ml}(170 \mathrm{mg} / \mathrm{dl}$ to $>10,000 \mathrm{mg} / \mathrm{dl})$ for all patients, $3267 \pm 2107 \mathrm{ng} / \mathrm{ml}(170 \mathrm{mg} / \mathrm{dl}$ to $>10,000 \mathrm{mg} / \mathrm{dl})$ for the group with a BCR $>20$ and $3402 \pm 1874 \mathrm{ng} / \mathrm{ml}(445 \mathrm{mg} / \mathrm{dl}$ to $>10,000 \mathrm{mg} / \mathrm{dl}$ ) for the group with a $\mathrm{BCR}=15-20$. High Ddimer levels $(>5,000 \mathrm{ng} / \mathrm{ml})$ were found in $36 \%$ of the total cases, in $39 \%$ of cases with a BCR $>20$ and in $31 \%$ of cases with a BCR of 15-20. The CRP was assessed in 167 patients. The mean values were $229 \pm 173 \mathrm{mg} / \mathrm{l}(1 \mathrm{mg} / \mathrm{dl}$ to $403 \mathrm{mg} / \mathrm{dl})$ for all of the patients, $110 \pm 80 \mathrm{mg} / \mathrm{l}(1 \mathrm{mg} / \mathrm{dl}$ to $362 \mathrm{mg} / \mathrm{dl})$ for the subgroup with BCR>20, and $132 \pm 111 \mathrm{mg} / \mathrm{l}(1 \mathrm{mg} / \mathrm{dl}$ to $403 \mathrm{mg} / \mathrm{dl}$ ) for the subgroup with a BCR 15-20. High CRP $(>50 \mathrm{mg} / \mathrm{l})$ was found in $70 \%$ of the total cases, in $71 \%$ of cases with a BCR $>20$, and in $70 \%$ of cases with a BCR 15 20. The $\mathrm{CBC}$ was tested in all patients. Severe anemia $(\mathrm{Hb}$ $<8 \mathrm{~g} / \mathrm{dl}$ ) was detected in $38 \%$ of cases with a BCR>20 and in $54 \%$ of cases with a BCR of 15-20. Leukocytosis or neutrophilia (leukocytes $>15,000 / \mu 1$, neutrophil count $>12,000 / \mu \mathrm{l}$ ) was detected in $38 \%$ of cases with a $\mathrm{BCR}>20$ and in $35 \%$ of cases with a BCR of 15-20. Leucopenia or neutropenia (leucocytes $<2,000 / \mu / 1$, neutrophil count $<1,000 / \mu \mathrm{l}$ ) was found in $13 \%$ of cases with $\mathrm{BCR}>20$ and in $15 \%$ of cases with a BCR of 15-20. Thrombocytopenia 


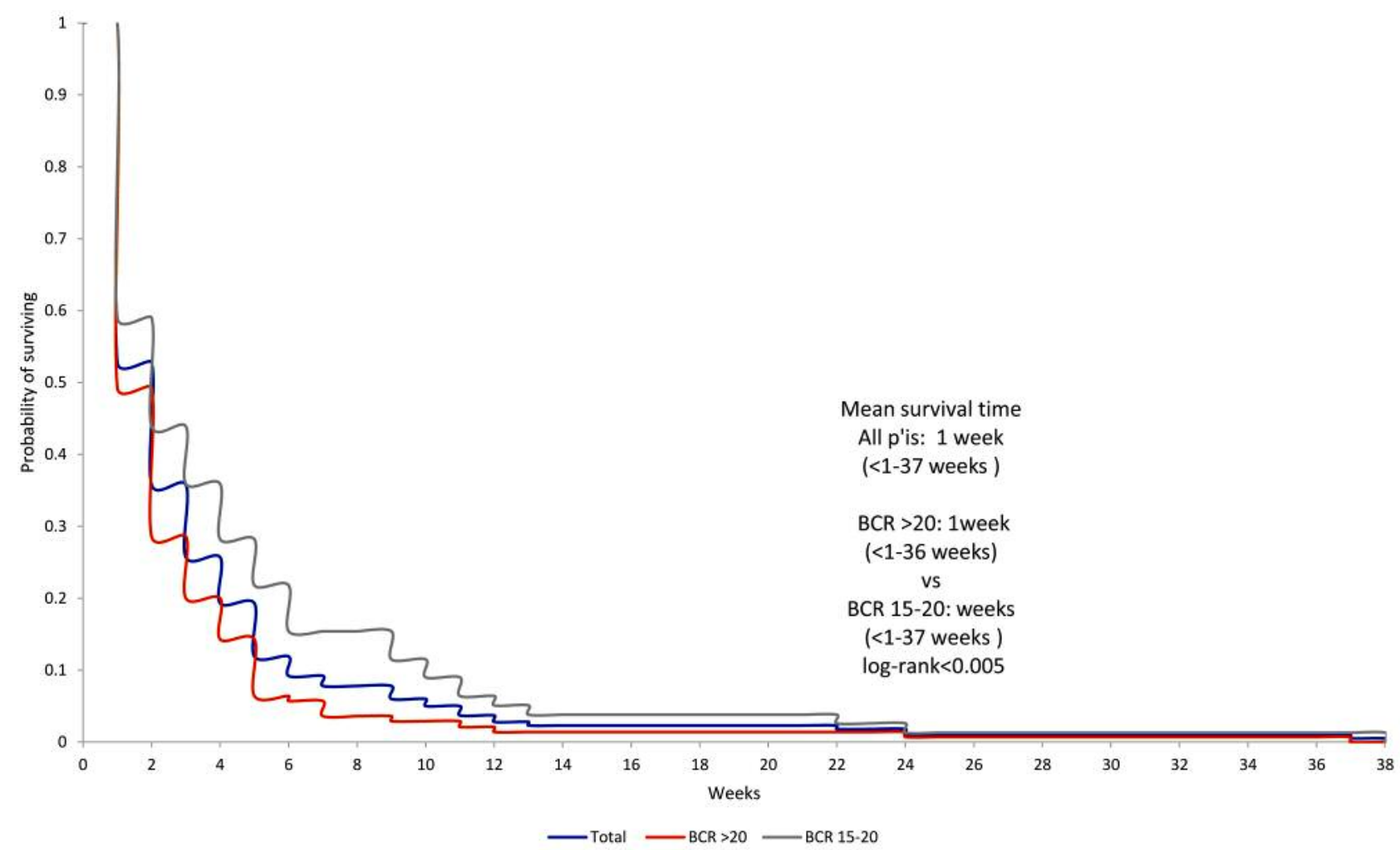

Figure 1. Survival curve of all patients and those with BCR $>20$ and BCR 15-20 groups. Log-rank test comparing BCR $>20$ with BCR 15-20.

Table II. Laboratory findings from 218 cancer patients with prerenal azotemia: comparisons between patients with BUN to Cr ratio (BCR)>20 and BCR 15-20.

\begin{tabular}{|c|c|c|c|c|}
\hline Characteristics & Total patients $(\mathrm{N}=218)$ & $\mathrm{BCR}>20(\mathrm{~N}=140)$ & BCR 15-20 (N=78) & $p$-Value \\
\hline High D-dimer $(\geq 5000 \mathrm{ng} / \mathrm{ml})$ & $63 / 175(36)$ & $43 / 111(39)$ & $20 / 64(31)$ & 0.32 \\
\hline High C-reactive protein $(\geq 50 \mathrm{mg} / \mathrm{l})$ & $125 / 178(70)$ & $79 / 112(71)$ & $46 / 66(70)$ & 0.91 \\
\hline Severe anemia $(\mathrm{Hb}<8 \mathrm{~g} / \mathrm{dl})$ & $95 / 218(44)$ & $53 / 140(38)$ & $42 / 78(54)$ & 0.028 \\
\hline Leukocytosis/neutrophilia & & & & \\
\hline $\begin{array}{l}(\text { Leucocytes } \geq 15,000 / \mu \mathrm{l} / \text { Neutrophil } \geq 12,000 / \mu \mathrm{l}) \\
\text { Leucopenia/neutropenia }\end{array}$ & $80 / 218(36)$ & $53 / 140(38)$ & $27 / 78(35)$ & 0.63 \\
\hline (Leucocytes $<2,000 / \mu / 1 /$ Neutrophil $<1,000 / \mu \mathrm{l}$ ) & $30 / 218(14)$ & $18 / 140(13)$ & $12 / 78(15)$ & 0.60 \\
\hline Thrombocytopenia (Platelet $<100,000 / \mu \mathrm{l}$ ) & $86 / 218(39)$ & $55 / 140(39)$ & $31 / 78(40)$ & 0.94 \\
\hline Thrombocytosis (Platelet $\geq 400,000 / \mu \mathrm{l}$ ) & $24 / 218(11)$ & $18 / 140(13)$ & $6 / 78(8)$ & 0.29 \\
\hline Presence of blasts or immature myeloid cells & $120 / 218(55)$ & $69 / 140(49)$ & $51 / 78(65)$ & 0.031 \\
\hline Percentage of urothelial cancer & $123 / 218(56)$ & $75 / 140(54)$ & $48 / 78(62)$ & 0.26 \\
\hline
\end{tabular}

(platelet count $<100,000 / \mu \mathrm{l}$ ) was detected in $39 \%$ of cases with a BCR $>20$ and in $40 \%$ of cases with a BCR 15-20. Thrombocytosis (platelet count $>400,000 / \mu \mathrm{l}$ ) was found in $13 \%$ of cases with a BCR $>20$ and in $8 \%$ of cases with a $\mathrm{BCR}$ of 15-20. The presence of blasts or immature myeloid cells was detected in $49 \%$ of cases with $\mathrm{BCR}>20$ and in $65 \%$ of cases with a BCR of 15-20. Urothelial cancers were present in $54 \%$ of cases with a BCR $>20$ and in $62 \%$ of cases with a BCR 15-20. By comparison, there was significantly more severe anemia $(p=0.028)$ and a greater number of blasts or immature myeloid cells in cases with a BCR of 15-20 than in patients with a $\mathrm{BCR}>20(p=0.031)$.

The median survival time for all patients was one week (range $=<1-37$ weeks). The median survival time was two 
weeks (range $=<1-37$ weeks) in cases with a BCR 15-20 (range $=<1-27$ weeks) and one week (range $=<1-36$ weeks) in cases with a $B C R>20$. Survival time was statistically different between the two groups $(p<0.005$, log-rank test; Figure 1). There were 111 patients $(51 \%)$, comprising 71 $(51 \%)$ cases with a BCR $>20$ and $40(51 \%)$ cases with a BCR 15-20, that had septicemia or infections as complications. The pre-death status identified in cases with BCR $>20$ and $\mathrm{BCR}=15-20$ were predominantly a loss of consciousness [132 $(94 \%), 8(6 \%)]$ or respiratory failure [71 $(91 \%), 7$ $(9 \%)]$, respectively.

\section{Discussion}

Cancer patients are at high risk for the development of AKI (1419), which is related to the production of inflammatory cytokines and results in an increased mortality rate (19). In this study, the cancer patients that had concurrent AKI died in a very short time, and the mean survival time was only one week. Production of inflammatory cytokines can be due to cancer itself or to responses of the patients to invasive procedures, therapies, or infections $(11,20)$. Similarly, AKI in cancer patients can be secondary to cancer itself, driven by reactions of patients to bacterial infection, chemotherapy, or surgery (1416). Half of our cases developed AKI due to other complications, such as septicemia or infection. As recurrent AKI is common in patients who have already been hospitalized with AKI, and because AKI is associated with an increased rate of death $(21,22)$, there is a need for clinicians to quickly identify risk factors and generate appropriate management plans (18).

Increased production of inflammatory cytokines can result in thromboembolic complications, cancer cachexia, and tumor progression, which result in poor prognoses $(11,12)$. In our study, before the onset of AKI, over $60 \%$ of patients had thromboembolic complications; of these, cerebral thrombosis and pulmonary venous obstructive syndrome were the most common $(11,12)$. Over $40 \%$ of patients had paraneoplastic syndromes, of which cancer cachexia was the most common. The levels of D-dimer were more than $5000 \mathrm{ng} / \mathrm{ml}$ in $36 \%$ of patients, and the CRP values were over $50 \mathrm{mg} / 1$ in $70 \%$ of patients. Elevated D-dimers and CRP values are indicators of venous thrombosis, are associated with increased levels of cytokines, and are predictors of a poor prognosis $(23,24)$.

A high BCR can be the result of high BUN, low creatinine levels, or both, although an increase in the ratio may also be due to a decrease in the blood flow to the kidneys and this may be more useful as a prognostic indicator of mortality (7). However, previous studies have shown that BCR fails to distinguish between prerenal and intrinsic AKI (25). In our study, the median survival time was worse in cases with BCR $>20$ than in cases with BCR 15-20. The higher BCR was probably related to an increased production of inflammatory cytokines, resulting in decreased renal blood flow. These consequences can accelerate thromboembolic complications, such as cerebral thrombosis (20).

In people who have cancer, anemia may be caused by inflammation, blood loss, or cancers that affect or spread to the bone marrow. Cancer treatments such as chemotherapy and radiation therapy may also cause or worsen anemia.

Anemia, leukocytosis, thrombocytosis, thrombocytopenia and the presence of immature myeloid cells and blasts in peripheral blood smears can be related to inflammatory cytokines and thromboembolic complications of the treatment of cancer patients (26-31). In our study, a more severe anemia and an increased number of blasts and immature myeloid cells characterized cases with BCR 15-20. We suspect that these symptoms were not related to the onset of AKI. However, we suggest that high BCR is related to an increased production of inflammatory cytokines and can promote cancer mortality.

Our study has several limitations. First, the data was collected retrospectively from cases in a single center. Second, cytokine levels were not measured in these patients. Finally, mental status changes and altered consciousness related to thromboembolic complications were seldom proved by imaging studies. All of these factors contributed to a limitation in data analysis.

\section{Conclusion}

Cancer patients with new-onset AKI with prerenal azotemia have a poor prognosis. The prevention of the acute inflammatory process and minimization of the risk of thrombosis and thromboembolic complications due to the response of patients to invasive procedures, therapies, or infections, are needed in therapeutic management.

\section{Conflicts of Interest}

The Authors declare that they have no competing interests in regard to this study.

\section{Authors' Contributions}

LT-Y collected and analyzed data and wrote the manuscript, LC-C offered the case, collected and analyzed data and wrote the manuscript.

\section{Acknowledgements}

The Authors wish to thank the oncology nursing staff for providing the best possible care for the patients of this study. The Authors would like to thank Uni-edit (www.uni-edit.net) for editing and proofreading this manuscript.

\section{References}

1 Makris K and Spanou L: Acute kidney injury: definition, pathophysiology and clinical phenotypes. Clin Biochem Rev 37: 85-98, 2016. PMID: 28303073. 
2 Srisawat $\mathrm{N}$ and Kellum JA: Acute kidney injury: definition, epidemiology, and outcome. Curr Opin Crit Care 17: 548-555, 2011. PMID: 24514101. DOI: 10.1097/MCC. 0000000000000067

3 Raghavan Murugan and John A Kellum: Acute kidney injury: what's the prognosis? Nat Rev Nephrol 7: 209-217, 2011. PMID: 21343898. DOI: 10.1038/nrneph.2011.13

4 Lee DW, Faubel S and Edelstein CL: Cytokines in acute kidney injury (AKI). Clin Nephrol 76: 165-173, 2011. PMID: 21888852. DOI: $10.5414 / \mathrm{cn} 106921$

5 Rabb H, Griffin MD, McKay DB, Swaminathan S, Pickkers P, Rosner MH, Kellum JA and Ronco C: Acute dialysis quality initiative consensus XIII Work Group. Inflammation in AKI: current understanding, key questions, and knowledge gaps. J Am Soc Nephrol 27: 371-379, 2016. PMID: 26561643. DOI: 10.1681/ASN.2015030261

6 Bellomo R, Bagshaw S, Langenberg C and Ronco C: Pre-renal azotemia: a flawed paradigm in critically ill septic patients? Contrib Nephrol 156: 1-9, 2007. PMID: 17464109. DOI 10.1159/000102008

7 Uchino S, Bellomo R and Goldsmith D: The meaning of the blood urea nitrogen/creatinine ratio in acute kidney injury. Clin Kidney J 5: 187-191, 2012. PMID: 2949752. DOI: 10.1093/ $\mathrm{ckj} / \mathrm{sfs} 013$

8 Manoeuvrier G, Bach-Ngohou K, Batard E, Masson D and Trewick D: Diagnostic performance of serum blood urea nitrogen to creatinine ratio for distinguishing prerenal from intrinsic acute kidney injury in the emergency department. BMC Nephrol 18: 173, 2017. PMID: 28545421. DOI: 10.1186/s12882 017-0591-9

9 Gallieni M, Cosmai L and Porta C: Acute kidney injury in cancer patients. Contrib Nephrol 193: 137-148, 2018. PMID 29393144. DOI: $10.1159 / 000484970$

10 Qin Y, Xu Q, Xu T, Yuan H and Hu F: Clinical characteristics of patients with malignancies combined with acute kidney injury. Int J Clin Exp Med 8: 11529-11533, 2015. PMID: 26379975.

11 Liaw CC, Chang H, Liao TY, Wen MS, Yu CT and Juan YH: The role of pulmonary veins in cancer progression from a computed tomography viewpoint. J Oncol 2016: 1872627, 2016 , PMID: 27746816. DOI: 10.1155/2016/1872627

12 Liaw CC, Chang H, Yang TS and Wen MS: Pulmonary venous obstruction in cancer patients. J Oncol 2015: 210916, 2015. PMID: 26425121. DOI: 10.1155/2015/210916

13 Liao TY, Hsu HC, Wen MS, Juan YH, Hung YH and Liaw CC: Iliofemoral venous thrombosis mainly related to iliofemoral venous obstruction by external tumor compression in cancer patients. Case Rep Oncol 9: 760-771, 2016. PMID: 27990113. DOI: $10.1159 / 000452943$

14 Jin J, Wang Y, Shen Q, Gong J, Zhao L and He Q: Acute kidney injury in cancer patients: A nationwide survey in China. Sci Rep 9: 3540, 2019. PMID: 30837515. DOI: 10.1038/s41598-01939735-9

15 César BN and Durão Júnior MS: Acute kidney injury in cancer patients. Rev Assoc Med Bras 66: s25-s30, 1992. PMID: 31939532. DOI: 10.1590/1806-9282.66.S1.25

16 Lam AQ and Humphreys BD: Onco-nephrology: AKI in the cancer patient. Clin J Am Soc Nephrol 7: 1692-1700, 2012. PMID: 31939532. DOI: 10.1590/1806-9282.66.S1.25

17 Gallieni M, Cosmai L and Porta C: Acute kidney injury in cancer patients. Contrib Nephrol 193: 137-148, 2018. PMID: 29393144. DOI: $10.1159 / 000484970$
18 Lameire N, Vanholder R, Van Biesen W and Benoit D: Acute kidney injury in critically ill cancer patients: an update. Crit Care 20: 209, 2016. PMID: 2748025. DOI: 10.1186/s13054-016-1382-6

19 Rosner MH and Perazella MA: Acute kidney injury in the patient with cancer. Kidney Res Clin Pract 38: 295-308, 2019. PMID: 3128436. DOI: 10.23876/j.krcp.19.042

20 Falanga A, Marchetti M and Vignoli A: Coagulation and cancer: biological and clinical aspects. J Thromb Haemost 11: 223-233, 2013. PMID: 23279708. DOI: 10.1111/jth.12075

21 Siew ED, Parr SK, Abdel-Kader K, Eden SK, Peterson JF, Bansal N, Hung AM, Fly J, Speroff T, Ikizler TA and Matheny ME: Predictors of recurrent AKI. J Am Soc Nephrol 27: 11901200, 2016. PMID: 26264853. DOI: 10.1681/ASN.2014121218

22 Hounkpatin HO, Fraser SDS, Glidewell L, Blakeman T, Lewington A and Roderick PJ: Predicting risk of recurrent acute kidney injury: a systematic review. Nephron 142: 83-90, 2019. PMID: 30897569. DOI: 10.1159/000497385

23 Lin Y, Liu Z, Qiu Y, Zhang J, Wu H, Liang R, Chen G, Qin G, Li Y and Zou D: Clinical significance of plasma D-dimer and fibrinogen in digestive cancer: A systematic review and metaanalysis. Eur J Surg Oncol 44: 1494-1503, 2018. PMID: 30100361. DOI: 10.1016/j.ejso.2018.07.052

24 Shrotriya S, Walsh D, Bennani-Baiti N, Thomas S and Lorton $\mathrm{C}$ : C-Reactive protein is an important biomarker for prognosis tumor recurrence and treatment response in adult solid tumors: A systematic review. PLoS One 10: e0143080, 2015. PMID: 26717416. DOI: 10.1371 /journal.pone. 0143080

25 Manoeuvrier G, Bach-Ngohou K, Batard E, Masson D and Trewick D: Diagnostic performance of serum blood urea nitrogen to creatinine ratio for distinguishing prerenal from intrinsic acute kidney injury in the emergency department. BMC Nephrol 18: 173, 2017. PMID: 28545421. DOI: 10.1186/s12882-017-0591-9

26 Adamson JW: The anemia of inflammation/malignancy: mechanisms and management. Hematology Am Soc Hematol Educ Program 2008: 159-165, 2008. PMID: 19074075. DOI: 10.1182/asheducation-2008.1.159

27 Weiss G, Ganz T and Goodnough LT: Anemia of inflammation. Blood 133: 40-50, 2019. PMID: 30401705. DOI: 10.1182/blood2018-06-856500

28 Connolly GC, Khorana AA, Kuderer NM, Culakova E, Francis $\mathrm{CW}$ and Lyman GH: Leukocytosis, thrombosis and early mortality in cancer patients initiating chemotherapy. Thromb Res 126: 113-118, 2010. PMID: 20684071. DOI: 10.1016/j. thromres.2010.05.012

29 Lin RJ, Afshar-Kharghan V and Schafer AI: Paraneoplastic thrombocytosis: the secrets of tumor self-promotion. Blood 124: 184-187, 2014. PMID: 24868077. DOI: 10.1182/blood-2014-03562538

30 Ghanavat M, Ebrahimi M, Rafieemehr H, Maniati M, Behzad MM and Shahrabi S: Thrombocytopenia in solid tumors: Prognostic significance. Oncol Rev 13: 413, 2019. PMID: 31205603. DOI: 10.4081 /oncol.2019.413

31 Musolino C, Allegra A, Pioggia G and Gangemi S: Immature myeloid-derived suppressor cells: A bridge between inflammation and cancer (Review). Oncol Rep 37: 671-683, 2017. PMID: 27922687. DOI: 10.3892/or.2016.5291

Received February 27, 2020

Revised March 10, 2020

Accepted March 11, 2020 